\title{
Decreased lung ischemia-reperfusion injury in rats after preoperative administration of cyclosporine and tacrolimus
}

\author{
B. Krishnadasan, MD \\ B. Naidu, MBBS \\ M. Rosengart, MD \\ A. L. Farr, BA \\ A. Barnes, PharmD \\ E. D. Verrier, MD \\ M. S. Mulligan, MD
}

Objectives: Calcineurin inhibitors reduce experimental reperfusion injury in the liver, brain, heart, kidney, and small bowel. These studies were undertaken to determine whether these agents are similarly protective against lung ischemiareperfusion injury.

Methods: Left lungs of male rats were rendered ischemic for 90 minutes and reperfused for as long as 4 hours. Treated animals received cyclosporine A (INN: ciclosporin; 1 or $5 \mathrm{mg} / \mathrm{kg})$ or tacrolimus $(0.2 \mathrm{mg} / \mathrm{kg}) 6$ hours before ischemia, at reperfusion, or 2 hours after reperfusion. Injury was quantitated in terms of tissue polymorphonuclear leukocyte accumulation (myeloperoxidase content), vascular permeability (iodine 125-labeled bovine serum albumin extravasation), and bronchoalveolar lavage leukocyte content. Separate tissue samples were processed for nuclear protein and cytokine messenger RNA.

Results: Treatment with cyclosporine $(5 \mathrm{mg} / \mathrm{kg})$ or tacrolimus $(0.2 \mathrm{mg} / \mathrm{kg}) 6$ hours before reperfusion reduced lung vascular permeability by $54 \%$ and $56 \%$ relative to control animals $(P<.03)$. The protective effects of cyclosporine and tacrolimus treatment before reperfusion correlated with $42 \%$ and $43 \%$ reductions in tissue polymorphonuclear leukocyte (myeloperoxidase) content $(P<.008)$ and marked reductions in bronchoalveolar lavage leukocyte accumulation $(P<.01)$. Administration of cyclosporine or tacrolimus at the time of reperfusion or 2 hours into the reperfusion period offered little or no protection. Animals treated before reperfusion also demonstrated marked reductions in nuclear factor $\kappa \mathrm{B}$ activation and expression of proinflammatory cytokine messenger RNA.

Conclusion: Cyclosporine and tacrolimus treatment before reperfusion was protective against lung ischemia-reperfusion injury in rats. The mechanism of these protective effects may involve the inhibition of nuclear factor $\kappa \mathrm{B}$, a central transcription factor mediating inflammatory injury. The decreased expression of cytokine messenger RNA indicates that both cyclosporine and tacrolimus may exert their protective effects at the pretranscriptional level.

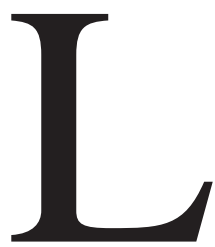

ung reperfusion injury occurs in as many as $25 \%$ of human lung transplant recipients. ${ }^{1}$ Efforts to alleviate reperfusion injury have focused on altering native host defenses, ${ }^{2}$ improving preservation techniques, ${ }^{3}$ and minimizing ischemic times. However, lung reper-

Copyright (C) 2002 by The American Association for Thoracic Surgery

$0022-5223 / 2002 \$ 35.00+0 \quad \mathbf{1 2 / 6 / 1 2 0 3 5 1}$

doi:10.1067/mtc.2002.120351 patibility complex II expression.

Cyclosporine A (CSA, INN: ciclosporin) and tacrolimus are immunosuppressive 


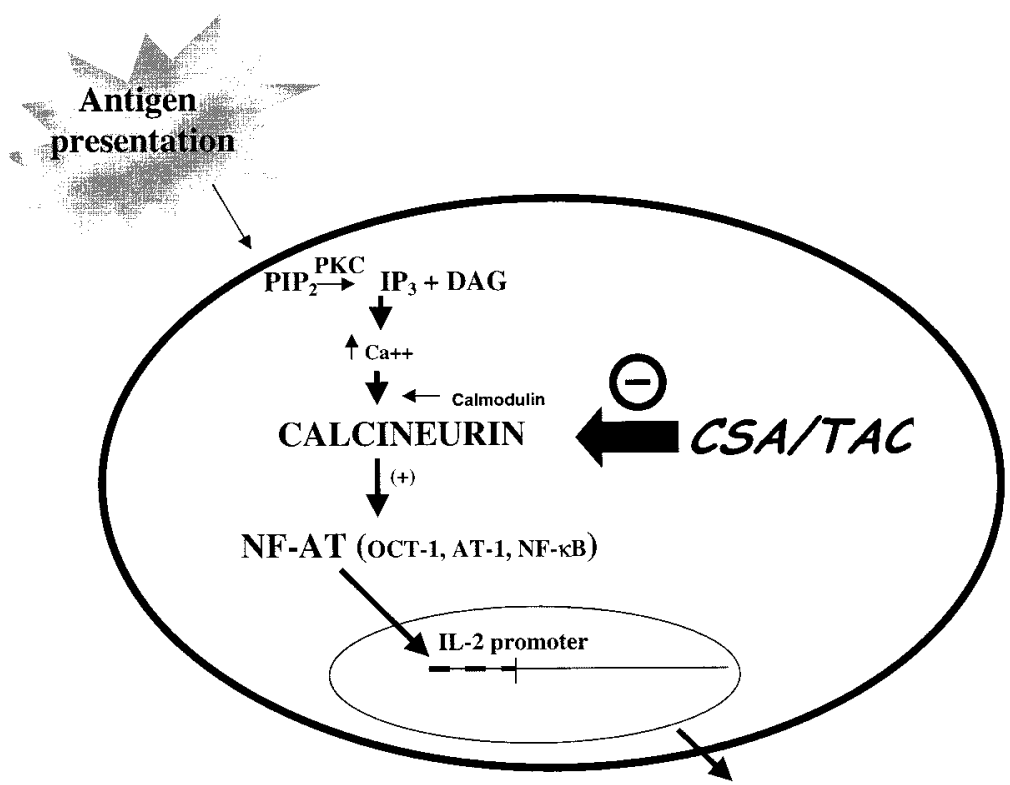

Figure 1. Immunomodulatory effects of CSA and tacrolimus (TAC). With antigen presentation, protein kinase C (PKC) activation leads to production of calcineurin, phophatase increasing production of various transcription factors, including NF-AT, OCT-1, AT-1, and NF- $\kappa$ B. Increase in NF-AT results in transcription of IL-2, powerful T-cell stimulant driving rejection. CSA and tacrolimus block this reaction by binding with cyclophilin and FK-binding protein to inhibit action of calcineurin.

agents that have been used in solid-organ transplantation for 2 decades. The immunomodulatory effects of CSA and tacrolimus involve the inhibition of the protein tyrosine phosphatase calcineurin (Figure 1). CSA is a hydrophobic undecapeptide that forms a complex with the cytoplasmic protein cyclophilin that inhibits calcineurin. Tacrolimus is a macrolide antibiotic that binds to a similar cytoplasmic protein, FK-binding protein, and blocks calcineurin 100 times more effectively than does the CSA-cyclophilin complex. The inhibition of calcineurin in turn reduces the expression of a number of nuclear transcription factors, including nuclear factor (NF) AT, Oct-1, AT-1, and NF- $\kappa$ B. All these transcription factors can bind to different sequences on the interleukin-2 promoter. By far the most critical, however, is NF-AT. Decreased nuclear transcription factor activity then results in a diminished production of interleukin-2 messenger RNA and protein, which subsequently blunts the T-cell response that mediates cellular rejection.

Whereas inhibition of NF-AT may be central to the immunomodulatory effects of CSA and tacrolimus, blockade of NF- $\kappa$ B may have broader anti-inflammatory effects. $\mathrm{NF}-\kappa \mathrm{B}$ has a range of activities, including modulation of cell growth and death, regulation of immune function, and apparent effects on acute reperfusion injury. ${ }^{4}$ The ability of CSA and tacrolimus to block NF- $\kappa$ B activation during acute cardiac reperfusion injury has been demonstrated. ${ }^{5} \mathrm{CSA}$ and tacrolimus have also been shown to reduce acute reperfu- sion injury of the liver ${ }^{6,7}$ and small bowel, ${ }^{8}$ but the mechanism mediating these protective effects has not been elucidated, and their impact on transcriptional regulation in this setting is unknown. At present no data exist regarding the effects of CSA or tacrolimus on lung ischemia-reperfusion injury.

In vitro studies have delineated the mechanism by which CSA and tacrolimus may inhibit NF- $\kappa \mathrm{B}$ activation. ${ }^{9,10}$ These studies suggest that inhibition of calcineurin blocks the degradation of $\mathrm{I}-\kappa \mathrm{B}$, the cytoplasmic protein that binds $\mathrm{NF}-\kappa \mathrm{B}$ in its inactive form. In addition, processing of proform precursors of NF- $\kappa \mathrm{B}$ to its functional heterodimeric form may be inhibited. The net result is a diminished concentration of active NF- $\kappa \mathrm{B}$ in the nucleus, which leads to decreased production of messenger RNA for proinflammatory cytokines, neutrophil adhesion molecules, procoagulant proteins, and vasoconstrictive substances. The reduction in NF- $\kappa \mathrm{B}$ activation and subsequent antiinflammatory effects therefore appear to act through mechanisms that are distinct from the immunomodulation that occurs through NF-AT inhibition.

Studies of calcineurin inhibition during organ ischemiareperfusion injury have methodologic problems that make clinical correlation difficult. Most animal studies investigating the effects of CSA and tacrolimus delivered the drugs during the week preceding the experiment to ensure that the animals had adequate drug levels before the ischemic insult. $^{6-8}$ Although this strategy was protective in these mod- 
els, it would be difficult to treat human transplant recipients accordingly, because the date of transplantation is determined by donor organ availability and therefore is unpredictable. One study that did administer the drug just before cardiac reperfusion demonstrated some protective effects that were dose dependent. ${ }^{5}$

We hypothesized that administration of CSA or tacrolimus would be protective in lung ischemia-reperfusion injury. Furthermore, treatment several hours before the ischemic insult might enhance the protective effects relative to treatment just before reperfusion or after it has begun. This would be akin to dosing patients as soon as an appropriate donor organ has been identified. In addition, we considered it important to investigate doses of CSA and tacrolimus that would be appropriate for human recipients. Previous animal studies have administered CSA at 10 to $25 \mathrm{mg} / \mathrm{kg}$ orally across 3 to 4 days or $5 \mathrm{mg} / \mathrm{kg}$ subcutaneously over 1 week. ${ }^{6-8}$ Such dosing schedules might be nephrotoxic or otherwise detrimental if applied to human recipients. Finally, knowing that CSA and tacrolimus attenuate reperfusion injury in heart, liver, and small bowel, and that in vitro studies indicate that these effects may be mediated through $\mathrm{NF}-\kappa \mathrm{B}$ blockade, we hypothesized that protective effects of these drugs would be associated with a demonstrable reduction in NF- $\kappa \mathrm{B}$ activation.

\section{Material and Methods}

\section{Reagents}

Commercial preparations of CSA (Novartis Pharmaceuticals Corporation, East Hanover, NJ) and tacrolimus (Fujisawa Healthcare, Inc, Deerfield, Ill) were obtained from the inpatient pharmacy at the University of Washington. All other reagents were purchased from Sigma (St Louis, Mo) unless otherwise specified.

\section{Animal Model}

Pathogen-free adult male Long-Evans rats (Simonsen Laboratories, Inc, Gilroy, Calif) weighing 280 to $320 \mathrm{~g}$ were used for all experiments. The University of Washington Animal Care Committee approved all experimental protocols. Animals were anesthetized with 30 to $35 \mathrm{mg}$ of intraperitoneally administered pentobarbital, shaved, and prepared for surgery. A 14-gauge angiocatheter was inserted into the trachea through a midline neck incision and secured with a $4-0$ braided suture. Animals were then placed on a Harvard Rodent Ventilator (Harvard Apparatus, Inc, Holliston, Mass) with an inspired oxygen content of $60 \%$, a rate of 80 breaths/min, and $2 \mathrm{~cm} \mathrm{H}_{2} \mathrm{O}$ of positive end-expiratory pressure. Maximal peak pressures were maintained below $10 \mathrm{~cm} \mathrm{H}_{2} \mathrm{O}$. All animals received $0.4 \mathrm{mg}$ atropine intramuscularly, and anesthesia was maintained with inhaled halothane. Dissection was conducted with an operating microscope, and a warming blanket was placed underneath each animal throughout the experiment.

A left anterolateral thoracotomy in the fifth intercostal space was performed. The left lung was mobilized atraumatically, and the inferior pulmonary ligament was divided sharply. Animals then received 50 units of intravenous heparin in saline solution (total volume $500 \mu \mathrm{L}$ ). Five minutes after heparin was administered, the left pulmonary artery, veins, and main stem bronchus were occluded with a noncrushing microvascular clamp. During the experiment the lungs were kept moist with periodic application of warm isotonic sodium chloride solution, and the incision was covered to minimize evaporative losses. The period of ischemia was constant at 90 minutes. At the end of the ischemic period the clamp was removed from the hilum, and the lung was allowed to ventilate and reperfuse for periods as long as 4 hours. Animals received subcutaneously $0.5 \mathrm{~mL}$ warm saline solution per hour to maintain hydration during the experiment. At the end of the reperfusion period a midline incision from the neck to the pubis was made to allow access to the chest and abdomen. Blood samples were obtained from the inferior vena cava just before the animal was killed. The heart-lung block was rapidly excised, and the pulmonary circulation was flushed through the main pulmonary artery with $20 \mathrm{~mL}$ isotonic sodium chloride solution. The lungs were then separated from the heart and mediastinal tissues and analyzed as outlined here. A time-matched sham control group underwent the same procedure except that the microvascular clamp was not applied to the hilum (thoracotomy alone).

Treated animals received CSA intravenously at $1 \mathrm{mg} / \mathrm{kg}$ or 5 $\mathrm{mg} / \mathrm{kg}$ or tacrolimus intravenously at $0.2 \mathrm{mg} / \mathrm{kg}$. Drugs were mixed in $500 \mu \mathrm{L}$ of sterile phosphate-buffered saline solution just before administration and then injected through the penile vein 5 minutes before reperfusion or 2 hours after removal of the hilar clamp. Additional groups of animals were treated with intravenous CSA or tacrolimus 6 hours before the beginning of the experiment. A control group of animals received cremaphor vehicle (the solvent for CSA and tacrolimus) at matched time points.

\section{Lung Permeability Index}

To quantitate lung injury related to ischemia and reperfusion, a lung permeability index was determined in the following manner. Iodine 125 -radiolabeled bovine serum albumin $\left({ }^{125} \mathrm{I}-\mathrm{BSA}\right)$ was obtained from NEN Life Science Products, Inc (Boston, Mass). Before use of the ${ }^{125}$ I-BSA in vivo, serial dilutions were performed to obtain an activity of 800,000 counts/min (cpm) per dose. This volume of ${ }^{125} \mathrm{I}$-BSA, approximately $2 \mu \mathrm{L}$ of the stock solution, was then brought to a final volume of $500 \mu \mathrm{L}$ in a $1 \%$ BSA and phosphate-buffered saline solution. Five minutes before removal of the hilar clamp or at an equivalent time in the sham control group, the ${ }^{125} \mathrm{I}$-BSA preparation was intravenously injected. Immediately before the animal was killed, $1 \mathrm{~mL}$ blood was drawn from the inferior vena cava. The heart-lung block was then excised and flushed as described previously. The radioactivity was then quantitated for the left and right lungs and for inferior vena cava blood with a gamma counter. The permeability index was then expressed as the ratio of the cpm in the left lung to the cpm in 1.0 $\mathrm{mL}$ of inferior vena caval blood as follows: permeability index $=$ $\mathrm{cpm}$ in left lung/cpm in $1.0 \mathrm{~mL}$ blood. This ratio corrected for any variation in systemic blood levels of radioactivity and provided a reproducible measure of lung microvascular permeability.

\section{Myeloperoxidase Assay}

Tissue myeloperoxidase (MPO) content was used to quantitate neutrophil accumulation in the lungs. After flushing, the pulmonary circulation the lungs were homogenized for 60 seconds in a solution of $0.5 \%$ hexadecyltrimethylammonium bromide and 
5-mmol/L ethylenediaminetetraacetic acid (EDTA) in 50-mmol/L potassium-phosphate buffer ( $\mathrm{pH}$ 6.0). Samples were then sonicated for 40 seconds in four 10 -second bursts. The homogenized tissue was maintained on ice between all tissue processing steps. Samples were then centrifuged at $2300 \mathrm{~g}$ for 30 minutes at $4^{\circ} \mathrm{C}$ and the supernatants were recovered. Assay buffer was composed of $0.0005 \%$ hydrogen peroxide and $0.167-\mathrm{mol} / \mathrm{L} o$-dianisidine dihydrochloride in $100-\mathrm{mmol} / \mathrm{L}$ potassium phosphate buffer $(\mathrm{pH} 6.0$ ). A $50-\mu \mathrm{L}$ aliquot of each sample was mixed with $1.45 \mathrm{~mL}$ of assay buffer, and the change in absorbence at $460 \mathrm{~nm}$ over 1 minute was recorded.

\section{Broncheoalveolar Lavage}

Additional animals underwent bronchoalveolar lavage (BAL) at the time they were killed. Through an extended median sternotomy, a 14-gauge angiocatheter was placed and the lungs were lavaged individually with $3.0 \mathrm{~mL}$ cold sterile saline solution. Individual lung BAL analysis was accomplished by clamping the contralateral hilum. At least $80 \%$ of the instilled fluid was recovered from each lung. This fluid was centrifuged $(1500 \mathrm{~g}$ for 8 minutes at $4{ }^{\circ} \mathrm{C}$ ) to pellet the cells. The red blood cells were lysed, and the pellet was resuspended in isotonic sodium chloride solution. Cells were then counted and a differential count was determined with a hemocytometer (Hausser Scientific Partnership, Horsham, Pa).

\section{Electrophoretic Mobility Shift Assay}

Additional left lungs were snap frozen at the end of the experimental protocols. These frozen tissue samples were ground into a fine powder and then suspended in $4.0 \mathrm{~mL}$ buffer containing 0.06\% Nonidet P-40 (Sigma Chemical Co, St Louis, Mo), 150$\mathrm{mmol} / \mathrm{L}$ sodium chloride, 10-mmol/L N-2-hydroxyethylpiperazine-N-2-ethanesulfonic acid (HEPES), 1-mmol/L EDTA, and 0.5$\mathrm{mmol} / \mathrm{L}$ phenylmethylsulfonyl fluoride (PMSF). The solution was then homogenized and centrifuged for 15 seconds at $12,000 \mathrm{~g}$. The pellet was discarded, and the supernatant was cooled to $4^{\circ} \mathrm{C}$. The supernatant was then centrifuged again for 15 seconds at $12,000 \mathrm{~g}$. The resultant pellet was suspended in $40-\mu \mathrm{L}$ buffer containing 40-mmol/L sodium chloride, 20-mmol/L HEPES, 0.2-mmol/L EDTA, 1.2-mmol/L magnesium chloride, 0.5-mmol/L PMSF, 0.5$\mathrm{mmol} / \mathrm{L}$ dichlorodiphenyltrichloroethane, $25 \%$ glycerol, $5-\mu \mathrm{g} / \mathrm{mL}$ aprotinin, and $5-\mu \mathrm{g} / \mathrm{mL}$ leupeptin at $4^{\circ} \mathrm{C}$ for 20 minutes. This solution was then centrifuged for 5 minutes, the pellet was discarded, and the supernatant containing the nuclear protein was stored at $-70^{\circ} \mathrm{C}$. Quantification of nuclear protein was performed with the bichinoic acid assay.

A $10 \mu \mathrm{g}$ sample of nuclear protein was incubated in a binding reaction with a double-stranded phosphorus 32-end-labeled oligonucleotide containing the human consensus NF- $\kappa \mathrm{B}$ binding sequence 5'-GCCATTGGGGATTTCCTCTTTACTGG-3'. This sequence is identical to the rat consensus NF- $\kappa \mathrm{B}$ site. The binding reaction was carried out at room temperature for 60 minutes, and the proteins were resolved on a $6 \%$ nondenaturing polyacrylamide gel at $100 \mathrm{~V}$ for 1 to 2 hours. The gels were dried and autoradiographed. Triplicate samples for each specimen were analyzed. Densitometry was performed with ImageJ software (version 1.2; Research Services Branch, National Institute of Mental Health, Bethesda, Md) to assess relative signal intensity.

\section{Ribonuclease Protection Assay}

Lung RNA was isolated in guanidine thiocyanate, with two rounds of acid phenol and chloroform extraction and alcohol precipitation. RNA integrity was confirmed by agarose gel electrophoresis and quantitated by optical density measurements at $260 \mathrm{~nm}$. RNA from each lung was evaluated with the Riboquant system (BD PharMingen, San Diego, Calif); rat cytokine template was used for detection of cytokines. In vitro transcription was carried out in transcription buffer supplemented with uridine triphosphate labeled with $\alpha$-phosphorus 32 (3000 Ci/mmol; Amersham Pharmacia Biotech, Inc, Piscataway, NJ) and T7 RNA polymerase. After deoxyribonuclease I treatment, the riboprobe was isolated by phenol and chloroform extraction and ammonium and ethanol precipitation. Labeling efficiency was determined by measuring Chernokov activity in a scintillation counter. Each riboprobe was diluted to the optimal activity (defined by the manufacturer), added to 20 $\mu \mathrm{g}$ of kidney RNA, heated to $90^{\circ} \mathrm{C}$, allowed to cool to $56^{\circ} \mathrm{C}$, and annealed overnight. After ribonuclease and proteinase $\mathrm{K}$ treatment, protected RNA hybrids were purified by phenol and chloroform extraction and ammonium acetate and ethanol precipitation and then separated by electrophoresis on $5 \%$ polyacrylamide/8-mol/L urea gels. Gels were dried and subjected to autoradiography with Kodak Biomax MS2 Film (Eastman Kodak Company, Rochester, NY). Triplicate samples for each specimen were analyzed. Densitometric analysis was done with ImageJ software (version 1.2).

\section{Statistical Analysis}

All data were presented as mean \pm SEM unless otherwise designated. Comparisons between multiple groups were made with analysis of variance. Comparisons between individual groups were made with a 2-tailed Student $t$ test.

\section{Results}

Four different control groups were generated. Negative control animals were those that did not undergo any surgical manipulation. Sham (thoracotomy only) control animals were placed on the ventilator and underwent a left thoracotomy and as long as 5.5 hours of mechanical ventilation but without occlusion of the hilum. A third group underwent thoracotomy and the occlusion of left hilum for 90 minutes. These animals were killed before any reperfusion. The final group was subjected to 90 minutes of ischemia followed by 4 hours of reperfusion (Figure 2). The permeability index in animals undergoing thoracotomy alone $(0.18 \pm 0.02)$ was double that seen in unmanipulated lungs $(0.09 \pm 0.006, P<$ .04 ). Animals that were subjected to 90 minutes of ischemia without reperfusion demonstrated increases in permeability that were not significantly different from the sham thoracotomy control group $(0.18 \pm 0.02$ vs $0.22 \pm 0.005, P=$ .20). However, a marked increase in permeability was seen in animals that underwent 4 hours of reperfusion after 90 minutes of ischemia $(0.75 \pm 0.01, P<.001$ relative to unmanipulated control group).

Positive control animals that received phosphate-buffered saline solution had a mean permeability index of $0.75 \pm 0.01$, and those receiving Cremaphor vehicle had a 


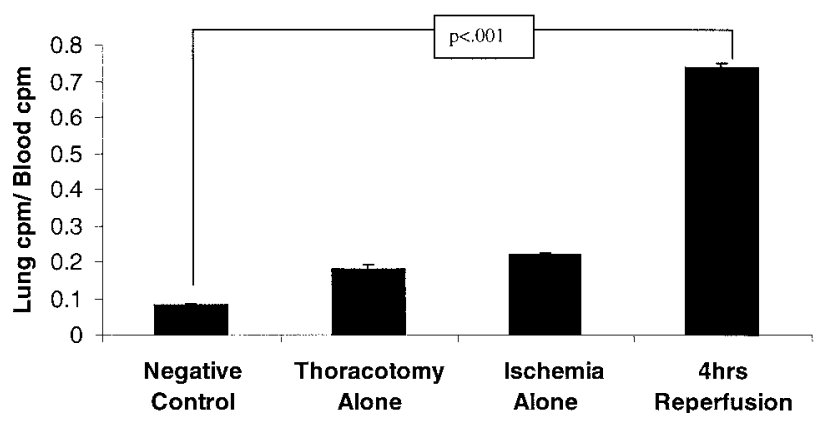

Figure 2. Left lung permeability in control animals. Lung vascular permeability was increased 7-fold in animals that underwent ischemia and reperfusion $(P<.001)$. Animals that underwent thoracotomy alone and ischemia alone also had statistically significant increases in permeability relative to unmanipulated control animals ( $P<.04 ; n=4$ in all experimental groups).

mean index of $0.76 \pm 0.03$ (Figure 3). Animals that received CSA or tacrolimus 2 hours after reperfusion did not demonstrate any reduction in vascular permeability relative to positive control animals. In contrast, treatment at the time of reperfusion (Figure 3 ) reduced permeability by $17 \%$ in animals receiving CSA at $5 \mathrm{mg} / \mathrm{kg}(P<.03)$ and by $18 \%$ in animals treated with tacrolimus at $0.2 \mathrm{mg} / \mathrm{kg}(P<.04)$. Administration of low-dose CSA $(1 \mathrm{mg} / \mathrm{kg})$ at reperfusion provided no protection relative to positive control animals. Treatment with tacrolimus or CSA at either dose 6 hours before the initiation of the experiment decreased lung injury significantly (Figure 3 ). The permeability index in animals pretreated with CSA at $1 \mathrm{mg} / \mathrm{kg}$ was reduced by $33 \%(P<$ $.008)$; with CSA at $5 \mathrm{mg} / \mathrm{kg}$ the reduction was $54 \%(P<$ .004 ), and with tacrolimus at $0.2 \mathrm{mg} / \mathrm{kg}$ the reduction was 56\% $(P<.003)$. Thus advance treatment with CSA and tacrolimus offered greater and more consistent protection than did treatment at the time of reperfusion or 2 hours after reperfusion had begun.

\section{MPO Activity}

MPO activity was measured in lungs from unmanipulated control animals and in lungs from animals subjected to 90 minutes of ischemia and $0,1,2,3$, and 4 hours of reperfusion (Figure 4). The change in absorbence at $460 \mathrm{~nm}$ across 1 minute in unmanipulated control animals was $0.06 \pm$ 0.002 . With ischemia only, MPO activity increased only slightly and not statistically significantly relative to unmanipulated control animals $(0.09 \pm 0.01)$.

Reperfusion was associated with a steady increase in MPO activity that was detectable at 2 hours after reperfusion and marked by $3(0.26 \pm 0.01)$ and 4 hours $(0.41 \pm$ $0.04, P<.002$; Figure 4). In an additional experiment with an extended time course, the tissue MPO content did not continue to increase at 6 or 8 hours and began to decrease at 12 hours (data not shown). MPO content thus appeared to peak after 4 hours of reperfusion.
MPO analysis was performed on lungs from animals that received CSA at $5 \mathrm{mg} / \mathrm{kg} 6$ hours before ischemia, at the time of reperfusion, or 2 hours after the onset of reperfusion. MPO was also assessed in lungs from animals that received tacrolimus at $0.2 \mathrm{mg} / \mathrm{kg} 6$ hours before ischemia (Figure 5). A statistically significant decrease in MPO content was seen only among animals that were treated in advance with CSA or tacrolimus. Animals treated with CSA or tacrolimus 6 hours before ischemia demonstrated $38 \%$ and $36 \%$ decreases in tissue neutrophil accumulation, respectively $(P<$ .008). Treatment with CSA or tacrolimus at the time of reperfusion or 2 hours after the onset of reperfusion was not associated with a reduction in lung MPO.

\section{BAL Leukocyte Content}

BAL analysis was undertaken to evaluate leukocyte content in the distal airways and alveolar compartment. Baseline BAL leukocyte counts were recorded in four groups: unmanipulated control group, sham thoracotomy control group, ischemia-alone control group (90 minutes of ischemia alone), and reperfusion injury group (90 minutes of ischemia followed by 4 hours of reperfusion; Figure 6). Animals undergoing sham thoracotomy or ischemia alone did not demonstrate a significant increase in BAL leukocyte content. However, a statistically significant increase in BAL leukocyte content was seen after 4 hours of reperfusion $(P<.005)$. The predominant cell type at the end of the reperfusion period in this group was the neutrophil, whereas all the other groups demonstrated mainly alveolar macrophages $(>95 \%)$.

As seen with tissue neutrophil accumulation, BAL cell count was reduced only in animals treated before ischemia with CSA or tacrolimus (Figure 6). Treatment at the time of reperfusion or 2 hours later did not reduce BAL leukocyte count (162 \pm 14 and $146 \pm 15$, respectively). In animals receiving CSA or tacrolimus 6 hours before ischemia, the BAL leukocyte count was $32 \%$ lower than the positive control values $(P<.01)$.

\section{Electrophoretic Mobility Shift Assay Analysis for NF- $\mathrm{KB}$}

Shown in Figure 7 is a representative electrophoretic mobility shift assay (EMSA) that details the expression of $\mathrm{NF}-\kappa \mathrm{B}$ in the nucleus of control and treated left lungs. There was no NF- $\kappa \mathrm{B}$ detected in the negative control animals. In contrast, significant activation of NF- $\kappa \mathrm{B}$ was apparent in the animals that underwent ischemia and reperfusion. The band specific for NF- $\kappa \mathrm{B}$ was delineated with a nonradiolabeled (cold) oligonucleotide. The location of this band is demonstrated in the lane marked "cold competition." Animals that received treatment before ischemia with CSA and tacrolimus appeared to have attenuated NF- $\kappa \mathrm{B}$ expression in the nucleus. These differences are quantitated in the densitometric analysis depicted below the autoradiograph. 


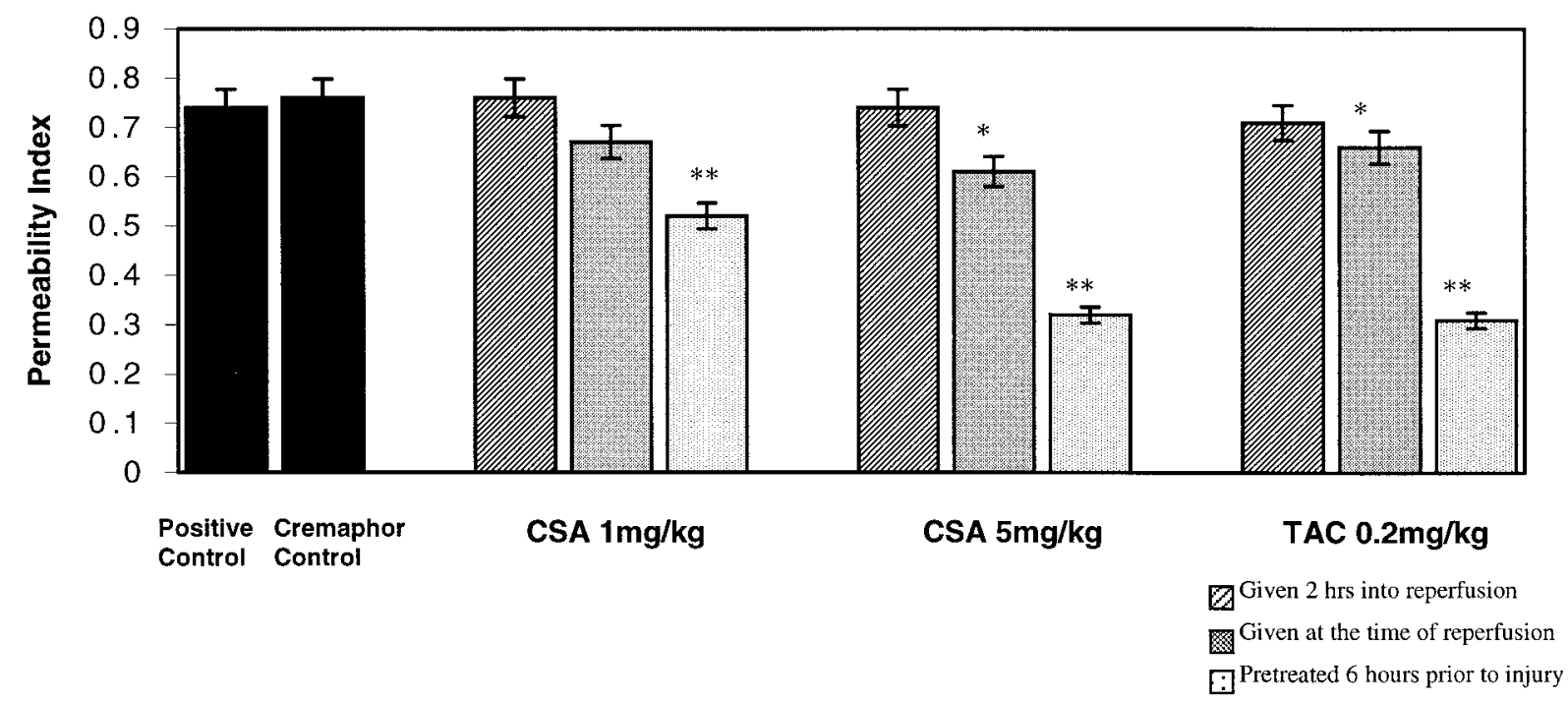

Figure 3. Lung permeability in animals receiving CSA at $1 \mathrm{mg} / \mathrm{kg}, \mathrm{CSA}$ at $5 \mathrm{mg} / \mathrm{kg}$, and tacrolimus at $0.2 \mathrm{mg} / \mathrm{kg}$. Two groups of positive control animals are shown, one receiving saline solution and one receiving cremaphor vehicle. There was no difference in permeability between these two groups. Animals treated 2 hours into reperfusion (diagonally filled bars) did not demonstrate any significant reduction in lung vascular injury at either dose of CSA or with tacrolimus ( $\mathrm{n}=\mathbf{6}$ in all experimental groups). Animals treated at reperfusion (shaded bars) with $5 \mathrm{mg} / \mathrm{kg}$ CSA and/or $0.2 \mathrm{mg} / \mathrm{kg}$ tacrolimus showed $17 \%$ and $18 \%$ reductions in lung vascular permeability (asterisk indicates $\boldsymbol{P}<.05$ ). Animals treated 6 hours before reperfusion (dotted bars) with CSA at 1 and $5 \mathrm{mg} / \mathrm{kg}$ and with tacrolimus at $0.2 \mathrm{mg} / \mathrm{kg}$ demonstrated $33 \%, 54 \%$, and $56 \%$ reductions in lung permeability (double asterisk indicates $\boldsymbol{P}<.003$ ).

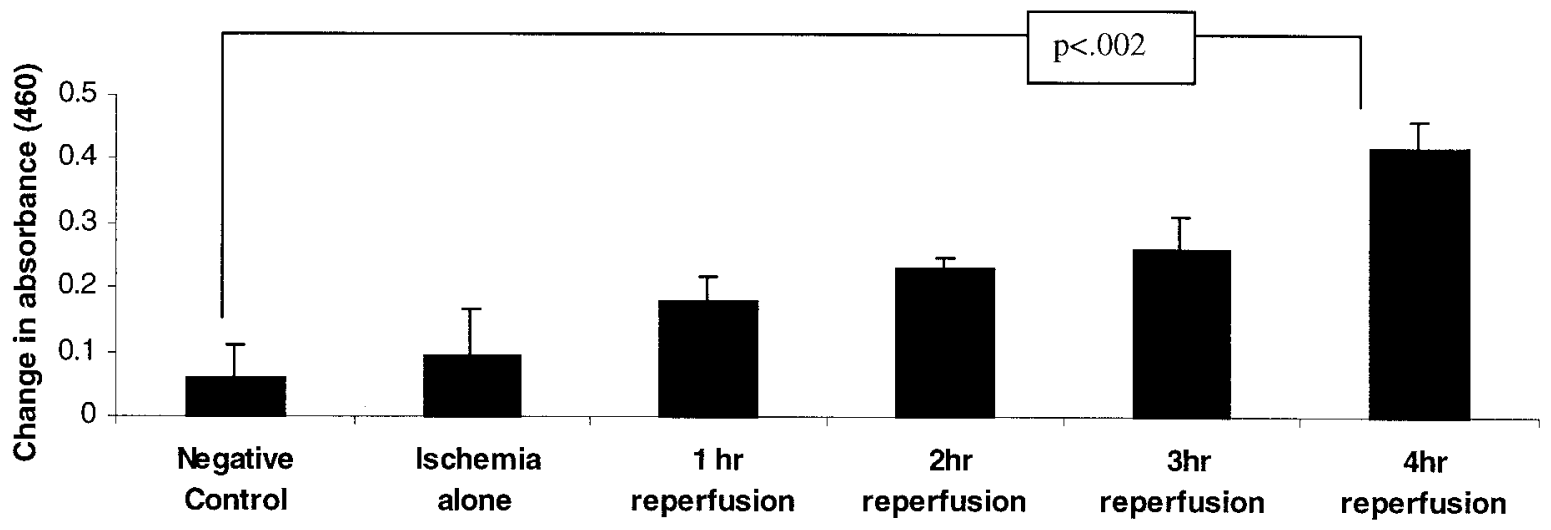

Figure 4. MPO content in control animals. There was steady increase in MPO contents of left lungs with increasing time of reperfusion. MPO content at 4 hours was statistically increased from unmanipulated control animals $(P<$ .002). Each experimental group included 4 animals.

\section{Ribonuclease Protection Assay}

Ribonuclease protection assays were performed on lung extracts from four experimental groups, unmanipulated negative control animals, animals that underwent 90 minutes of ischemia and 4 hours of reperfusion, and animals that underwent ischemia and reperfusion after advance treatment with CSA at $5 \mathrm{mg} / \mathrm{kg}$ or tacrolimus at $0.2 \mathrm{mg} / \mathrm{kg}$ (Figure 8). In unmanipulated control animals there were few transcriptional products in the left lung. In contrast, animals that underwent ischemia and reperfusion of the left lung dem- onstrated significantly increased messenger RNA expressions for a variety of cytokines (IL-3, IL-5, IL-1 $\beta$, tumor necrosis factor $\alpha$ (TNF- $\alpha$ ), IL-2, and interferon $\gamma$ ). The housekeeping genes demonstrated similar activities in all lanes and are shown at the bottom of the gel. This indicates that loading was equal, and relative differences in cytokine messenger RNA expressions assessed by densitometry are therefore meaningful and valid. In injured lungs from animals treated before ischemia with CSA or tacrolimus, there were decreased expressions of several inflammatory and 


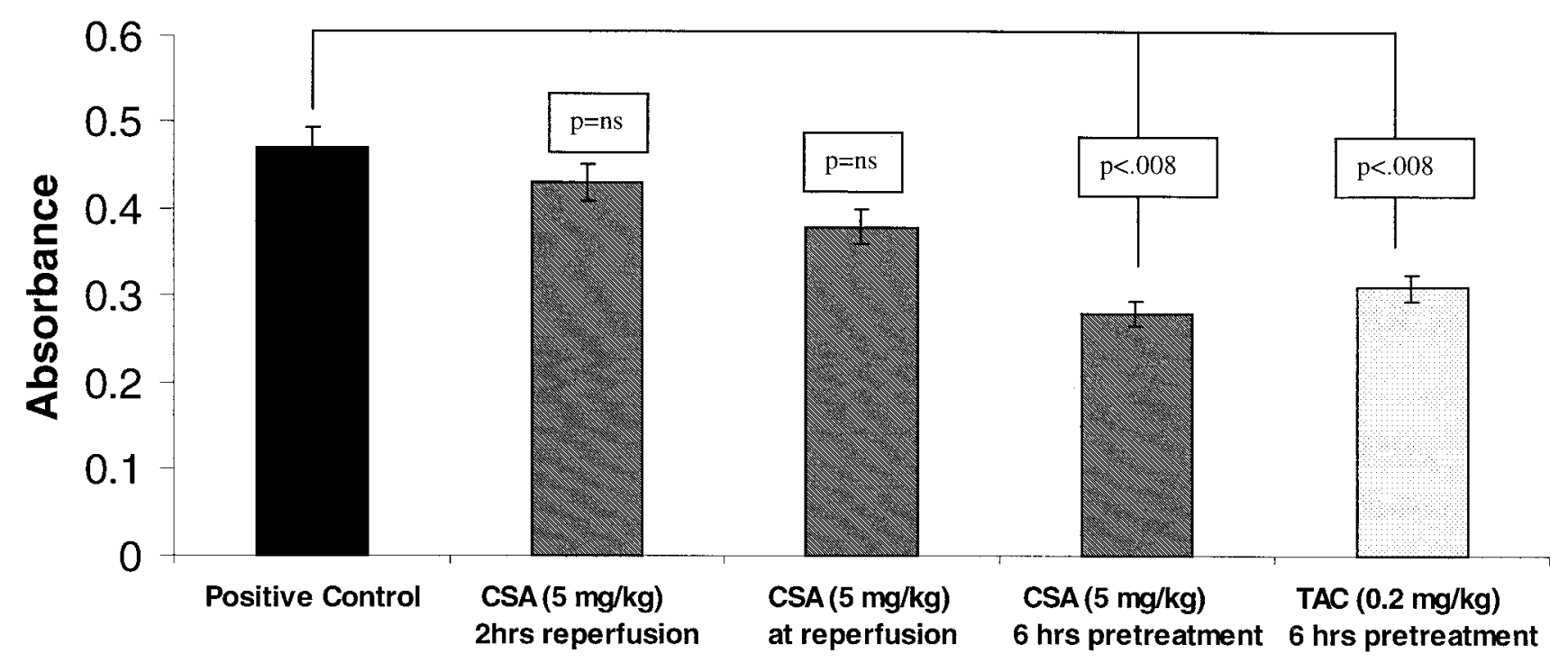

Figure 5. MPO activity in treated animals. Tissue neutrophil accumulation was modestly decreased in animals receiving CSA at $5 \mathrm{mg} / \mathrm{kg} 2$ hours after reperfusion and just before reperfusion, but decrease was not significant (ns). Animals that received CSA at $5 \mathrm{mg} / \mathrm{kg}$ and tacrolimus (TAC) at $0.2 \mathrm{mg} / \mathrm{kg} 6$ hours before experiment demonstrated $38 \%$ and $36 \%$ decreases in MPO content, respectively. These were statistically significant $(P<.008)$. Each experimental group included 4 animals.

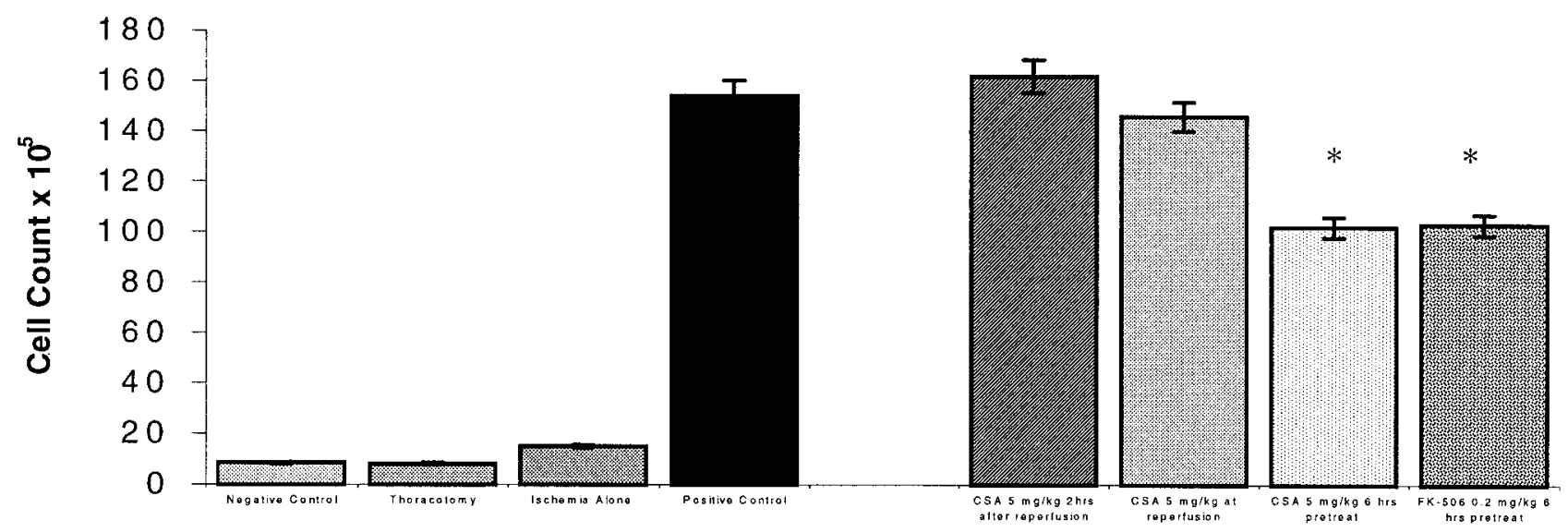

Figure 6. BAL cell count increased significantly in those animals undergoing ischemia followed by reperfusion relative to unmanipulated control animals $(P<.005)$. Small increases in cell count were seen with thoracotomy alone and with ischemia alone, but these increases were not significant. Predominant cell type in animals was alveolar macrophage, and most cells in unperfused lungs were neutrophils. Each experimental group included 6 animals. No relative decrease in alveolar cell count was seen in animals that received CSA at $5 \mathrm{mg} / \mathrm{kg}$ after $2 \mathrm{hours}$ of reperfusion or at time of reperfusion. However, significant decrease in alveolar leukocyte accumulation was seen in animals that received CSA at $5 \mathrm{mg} / \mathrm{kg}$ and tacrolimus (TAC) at $0.2 \mathrm{mg} / \mathrm{kg} 6$ hours before experiment, resulting in 32\% increase in BAL cell counts. Asterisk indicates $P<.01$.

regulatory cytokines relative to positive control lungs. These differences were quantitated in the densitometric analysis shown in Figure 9.

\section{Discussion}

The utility of CSA and tacrolimus for induction and maintenance immunosuppressive therapy after solid-organ trans- plantation has been demonstrated during the past 20 years. ${ }^{11}$ The immunomodulatory effects are mediated through transcriptional blockade of IL-2 production. These studies explored the possibility that these calcineurin inhibitors regulate inflammatory effects through a different transcriptional mechanism. One isolated study demonstrated that administration of CSA after reperfu- 


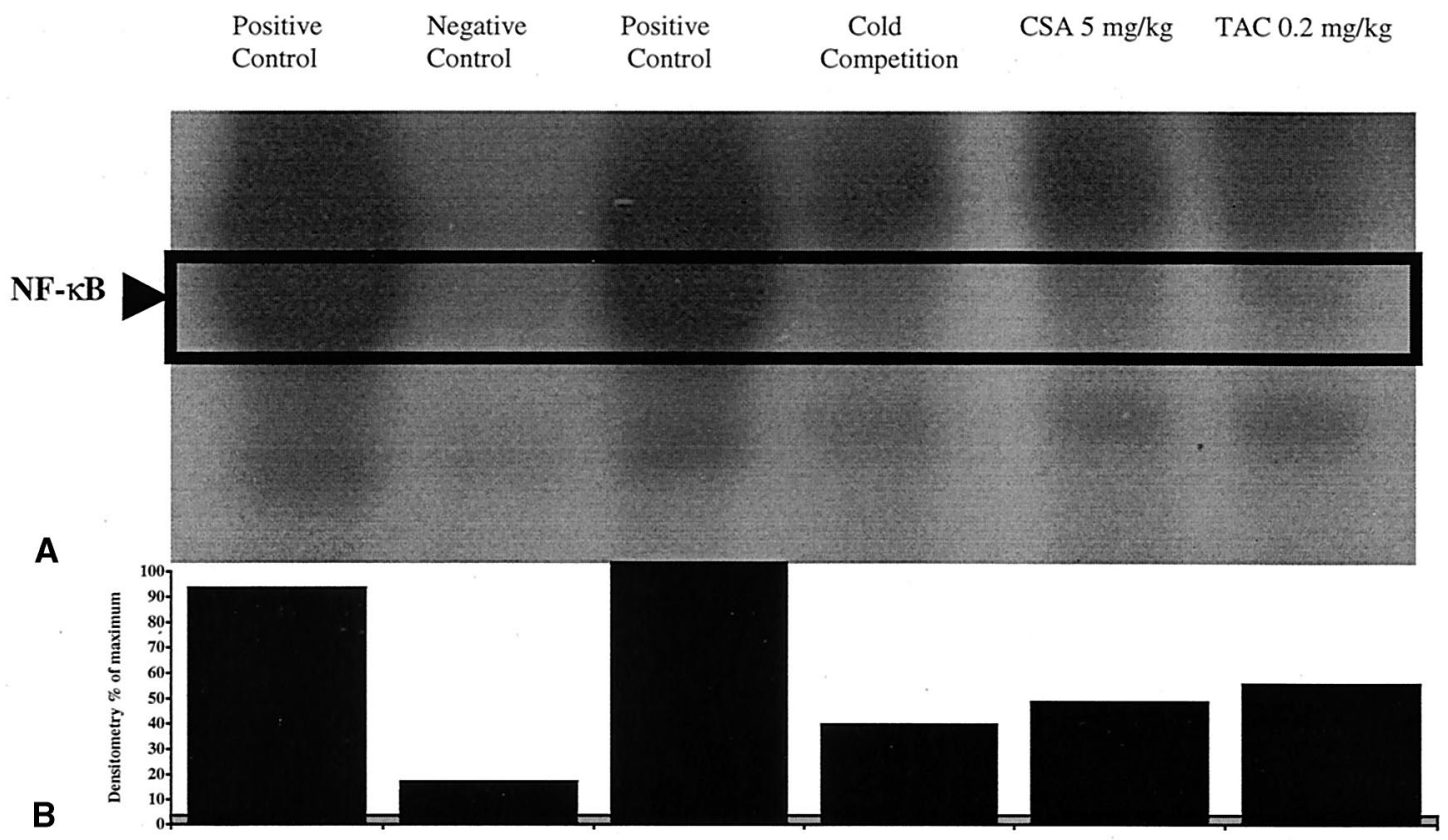

Figure 7. EMSA for nuclear protein expression of NF- $\kappa$ B. A, Area of interest is boxed. Far left lane shows extract from injured positive control lung that underwent ischemia followed by $\mathbf{4}$ hours of reperfusion. Second lane shows unmanipulated negative control lung. Third lane shows another positive control for side-by-side comparison. Fourth lane (Cold Competition) shows lung treated with nonradiolabeled NF- $\kappa$ B oligonucleotide that antagonizes radiolabeled oligonucleotide. Band specific for NF- $\kappa$ B drops out at this time. Far right lanes demonstrate absence of NF- $\kappa$ B expression in animals treated with CSA and tacrolimus 6 hours before reperfusion. B, Densitometric results corresponding to lanes on gel.

sion was protective against cardiac ischemia-reperfusion injury. ${ }^{12}$ This group studied isolated rabbit hearts that were perfused with buffer on a Langendorff apparatus. The ischemic time was limited to 30 minutes, and CSA was given 10 minutes into reperfusion. This is consistent with our finding that some protection was afforded by higher dose of CSA given at the time of reperfusion. However, in our study lung vascular permeability was not decreased in animals receiving CSA or tacrolimus after the onset of reperfusion (Figure 3). This is supportive of a transcriptional regulatory mechanism of action. Specifically, CSA and tacrolimus may modulate ischemia and reperfusion through blockade of NF- $\kappa$ B. Ischemia alone or ischemia followed by a short period of reperfusion activates NF- $\kappa$ B. ${ }^{13}$ Thus the blockade of NF- $\kappa$ B activation would be most effective if the intervention were to be performed before ischemia.

Protection from reperfusion injury is correlated with a decreased expression of NF- $\kappa \mathrm{B}$, as seen in the EMSA in Figure 7. Selective blockade of TNF- $\alpha$ with a polyclonal rat anti-TNF- $\alpha$ antibody afforded $45 \%$ protection from reperfusion injury, and combined blockade with anti-TNF- $\alpha$ and anti-IL-1 $\beta$ antibodies provided $60 \%$ protection (unpublished data). The degree of protection offered by CSA or TAC pretreatment (54\%-56\%) is therefore impressive.
Greater protection may be difficult to achieve because of incomplete transcriptional blockade or redundancy in proinflammatory mediators released in the lung.

The protection from vascular injury seen with calcineurin inhibitors administered 6 hours before ischemia was correlated with a decrease in neutrophil accumulation in both lung tissue and the alveolar compartment. Only animals treated before ischemia with CSA or tacrolimus demonstrated significant reductions in tissue neutrophil accumulation. These findings support conclusions of earlier studies regarding the ability of CSA and tacrolimus to reduce polymorphonuclear neutrophil accumulation in reperfused heart and liver. ${ }^{5,14}$

The EMSA suggests that NF- $\kappa \mathrm{B}$ activation was blocked in the animals that received CSA or tacrolimus before ischemia. This is the first direct demonstration of NF- $\kappa \mathrm{B}$ blockade by calcineurin inhibitors in an intact animal model. Others have assumed that NF- $\kappa \mathrm{B}$ is involved because I- $\kappa \mathrm{B}$ activity is preserved with tacrolimus treatment. ${ }^{5}$ Multiple investigators have established that NF- $\kappa \mathrm{B}$ activation is decreased by calcineurin inhibitors in vitro. ${ }^{15,16}$ This phenomenon has been investigated specifically in human bronchial epithelial cells ${ }^{17}$ and suggests that these events may be important in the development of acute lung inflammation. Several mechanisms through which calcineurin in- 


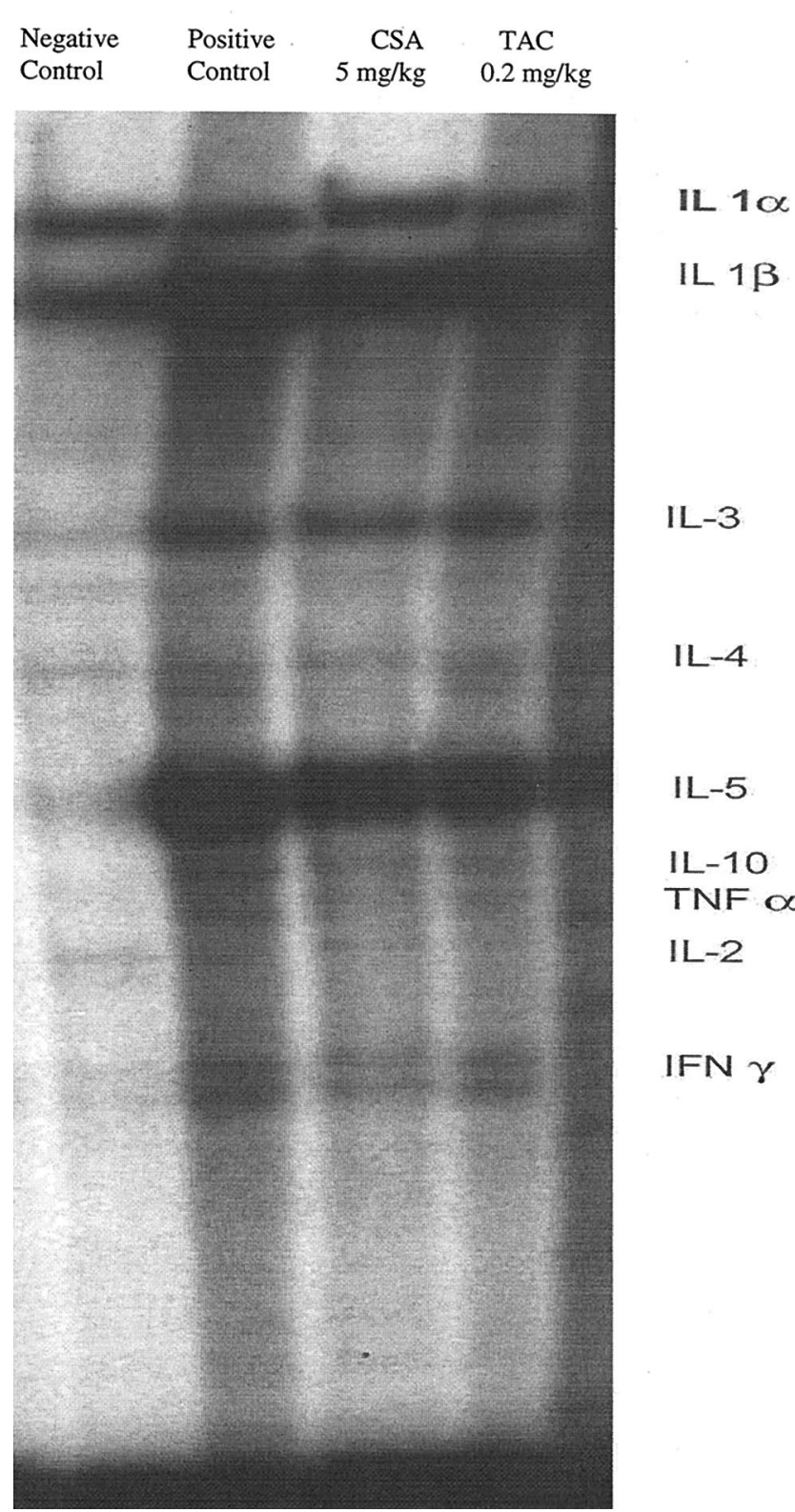

Figure 8. Ribonuclease protection assay. Four experimental groups are shown: negative control, positive control, and animals treated with $5 \mathrm{mg} / \mathrm{kg}$ CSA and $0.2 \mathrm{mg} / \mathrm{kg}$ tacrolimus (TAC) 6 hours before reperfusion. Housekeeping genes shown at bottom of gel demonstrate equal loading of RNA in all experimental groups. IFN, Interferon.

hibitors may decrease NF- $\kappa \mathrm{B}$ activity have been postulated. Calcineurin affects cellular kinetics and activation through its action as a calcium- and calmodulin-dependent serine and threonine phosphatase. It is believed that calcineurin blockade results in the inactivation of the $20 \mathrm{~S}$ proteasome. The $20 \mathrm{~S}$ proteasome is the site of degradation of $\mathrm{I}-\kappa \mathrm{B}$, the cytoplasmic inhibitor of NF- $\kappa \mathrm{B}$. Calcineurin also appears to facilitate processing of NF- $\kappa$ B proforms (p105) to the active heterodimer (p65). The inactivation of the $20 \mathrm{~S}$ proteasome by calcineurin inhibitors thus results in the decreased production of active NF- $\kappa \mathrm{B}$ and the preservation of cytoplasmic stores of $\mathrm{I}-\kappa \mathrm{B}$.

$\mathrm{NF}-\kappa \mathrm{B}$ blockade by CSA and tacrolimus correlates with the decreased expressions of phlogistic cytokine messenger RNA seen with the ribonuclease protection assay. Pretranscriptional blockade of $\mathrm{NF}-\kappa \mathrm{B}$ provided by CSA and tacrolimus would explain the diminution in expression of a wide variety of cytokines. TNF- $\alpha$ expression is regulated through some NF- $\kappa \mathrm{B}-$ dependent mechanism. ${ }^{14} \mathrm{NF}-\kappa \mathrm{B}$ activation has also been linked to the production of intracellular adhesion molecule 1, P-selectin, and IL-8. ${ }^{18}$ The decreased production of these adhesion molecules, chemokines, and cytokines seen with calcineurin inhibitors therefore may result in the decreased leukocyte accumulation seen in the tissue and alveolar compartment of the lung (Figures 5 and 6). Ultimately, these effects may reflect the amelioration of tissue injury seen with CSA and tacrolimus treatment.

The protection provided by calcineurin inhibitors has also been associated with inhibition of the mitochondrial transition pore opening ${ }^{19,20}$ and with variable effects on nitric oxide and endothelin metabolism. ${ }^{21,22}$ These mechanisms may also be relevant in a model of lung ischemiareperfusion, and further investigation is needed to elucidate the relevance of these pathways in this model. Most studies of the mitochondrial transition pore have been done in models of liver and heart reperfusion injury. Mitochondrial transition pore changes may be more important in these tissues than in the lung, because heart and liver appear to have a higher concentration of mitochondria.

Protection afforded by calcineurin inhibitors may also be mediated through amelioration of postischemic vasoconstriction. Tacrolimus appears to preserve the activity of inducible nitric oxide synthase during rat brain ischemiareperfusion injury, ${ }^{22}$ and both CSA and tacrolimus may suppress endothelin 1 production in rat small-bowel ischemia-reperfusion. ${ }^{23}$ These mechanisms may be particularly relevant to the pulmonary circulation, where amelioration of postischemic vasoconstriction may improve ventilationperfusion mismatch and overall lung function.

CSA and tacrolimus can cause vasoconstriction in the renal vascular bed. ${ }^{24}$ If such effects were seen in the pulmonary circulation, alteration of Starling forces would limit the edema seen with reperfusion injury. To characterize the acute effects of CSA and tacrolimus on pulmonary vasomotor tone, pulmonary arterial pressures were measured in rats after administration of the calcineurin inhibitors. Pulmonary arterial pressures were not altered in animals receiving CSA or tacrolimus for 30 minutes after administration of the drug (data not shown). It thus appears that the 

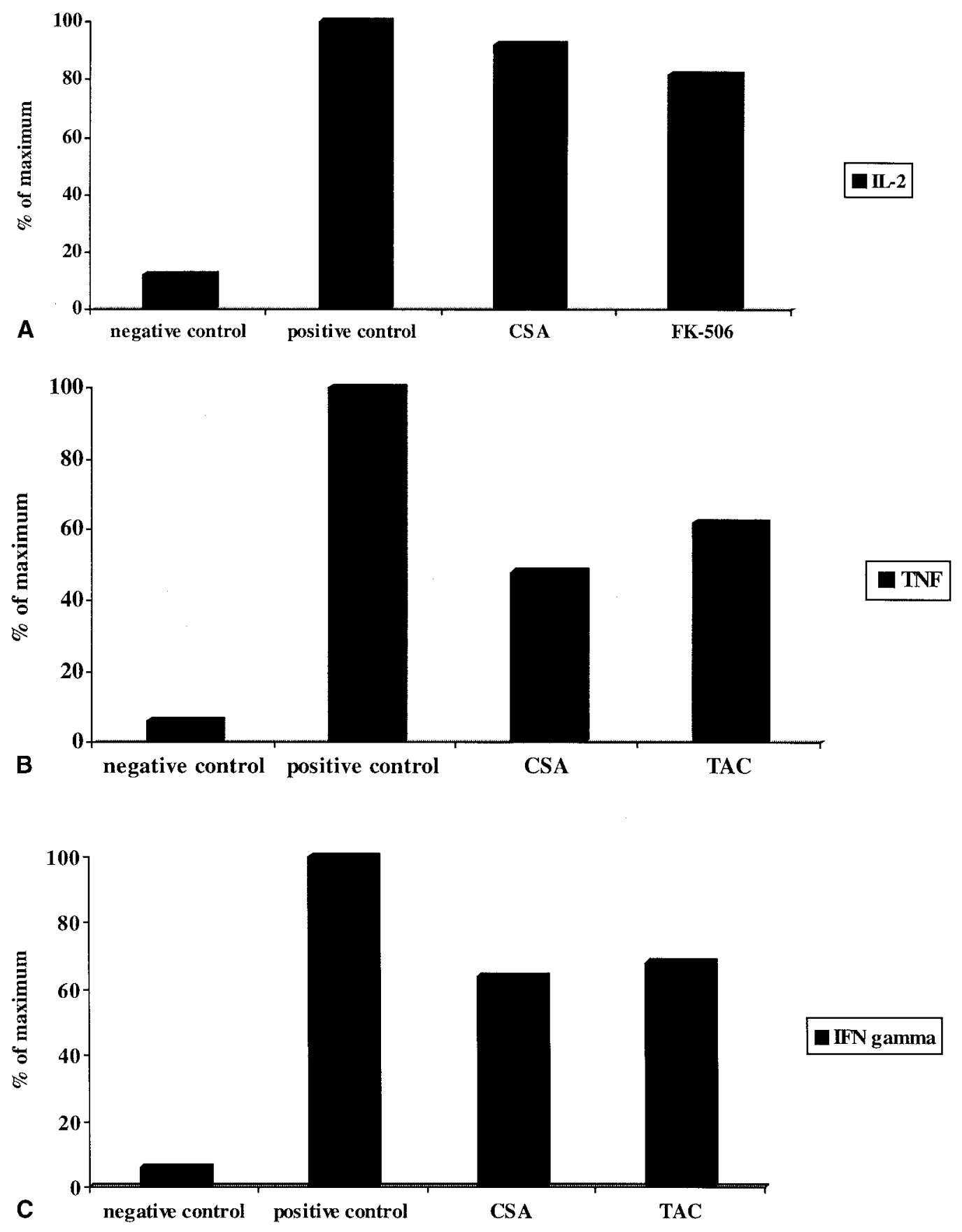

IFN gamma

Figure 9. Densitometric analyses for ribonuclease protection assay in Figure 8. Illustrated are samples from negative control animals, positive control animals, and animals treated with $5 \mathrm{mg} / \mathrm{kg} \mathrm{CSA}$ and $0.2 \mathrm{mg} / \mathrm{kg}$ tacrolimus (TAC, FK-506) 6 hours before reperfusion. There were generalized decreases in expressions in treatment groups, as seen quantitatively in densitometric analyses. IL-2 (A), TFN- $\alpha$ (B), and interferon $\gamma$ (C) messenger RNA expressions were decreased in animals treated with CSA and tacrolimus.

protective effects of CSA and tacrolimus are not related to drug-induced pulmonary vasoconstriction.

The potential for use of CSA or tacrolimus as advance treatment for human lung transplant recipients is contingent on the ability to deliver an adequate dose of calcineurin inhibitor at the appropriate time. Other studies have administered nephrotoxic doses of CSA $(10-25 \mathrm{mg} / \mathrm{kg})$ to animals to demonstrate protective effects. ${ }^{6-8}$ In this study we treated the study animals with clinically relevant doses of CSA (1 and $5 \mathrm{mg} / \mathrm{kg}$ intravenously) and tacrolimus $(0.2 \mathrm{mg} / \mathrm{kg})$. 
Significant protection was associated with advance treatment at both dose levels. CSA at $1 \mathrm{mg} / \mathrm{kg}$ is a dose that is commonly used for patients with impaired creatinine clearance, so the doses used in these studies appear to be both clinically relevant and safe. Ultimately the effectiveness of this particular treatment strategy needs to be systematically studied in human beings.

In conclusion, advance treatment of rats with CSA and tacrolimus decreased lung ischemia-reperfusion injury. The protection afforded by calcineurin inhibitors was associated with a decrease in neutrophil accumulation in the lung tissue and the alveolar compartment. The mechanism mediating protection may involve the blockade of the transcription factor NF- $\kappa \mathrm{B}$, and this blockade appears to result in a decreased expression of proinflammatory cytokines.

\section{References}

1. Meyers BF, Lynch J, Trulock EP, Guthrie TJ, Cooper ID, Patterson GA. Lung transplantation: a decade of experience. Ann Surg. 1999; 230:362-7

2. Suda T, Mora BN, D'Ovidio F, Hiratsaku M, Cooper JD, Zhang W, et al. In vivo adenovirus-mediated endothelial nitric oxide synthase gene transfer ameliorates lung allograft ischemia-reperfusion injury. $J$ Thorac Cardiovasc Surg. 2000;119:297-304.

3. Wittwer T, Walder T, Fehrenbach A, Elki S, Haverich A. Improvement of pulmonary preservation with Celsior and Perfadex: impact of storage time on early post-ischemic lung function. J Heart Lung Transplant. 1999;18:1198-201.

4. Baeuerle PA, Baltimore D. NF- $\kappa$ B: ten years later. Cell. 1996;87:1320.

5. Squadrito F, Altavilla D, Squadrito G, Saitta A, Deodato B, Arlotta M, et al. Tacrolimus limits polymorphonuclear leucocyte accumulation and protects against myocardial ischaemia-reperfusion injury. $J \mathrm{Mol}$ Cell Cardiol. 2000;32:429-40.

6. Travis DL, Fabia R, Netto GG, Husberg BS, Goldstein RM, Klintman $\mathrm{GB}$, et al. Protection by cyclosporine A against normothermic liver ischemia-reperfusion in pigs. $J$ Surg Res. 1995;75:116-26.

7. Dhar DK, Takemoto YI, Nagasue N, Uchida M, Oho T, Nakamura T. FK-506 maintains cellular calcium hemostasis in ischemia-reperfusion injury of the canine liver. $J$ Surg. 1996;60:142-6.

8. Puglisi RN, Strande L, Santos M, Scheulte G, Hewitt CW, Whalen TV. Beneficial effects of cyclosporine and rapamycin in small bowel ischemic injury. J Surg Res. 1996;65:115-8.

9. Meyer S, Kohler O, Joly A. Cyclosporine A is an uncompetitive inhibitor of proteasome activity and prevents NF- $\kappa \mathrm{B}$ activation. FEBS Lett. 1997;413:354-8.

10. Hughes K, Antonsson A, Grundstrom T. Calmodulin dependence of NF $\kappa$ B activation. FEBS Lett. 1995;44:132-6.

11. Gorantla VS, Barker JH, Jones JW, Prabhune K, Maldonado C, Granger DK. Immunosuppressive in transplantation: mechanism of action and current anti-rejection strategies. Microsurgery. 2000;20: 420-8.

12. Weinbrenner C, Liu OS, Downey IM, Cohen MV. Cyclosporine A limits myocardial infarction size even when administered after the onset of ischemia. Cardiovasc Res. 1998;38:678-84.

13. Canty TG, Boyle EM, Parr A, Morgan EN, Verrier ED, Pohlman TH. Oxidative stress induces NF- $\kappa \mathrm{B}$ nuclear translocation without degradation of IкB. Circulation. 1999;100:1361-4.

14. Garcia-Criado FI, Palma-Vargas JM, Valdunciel-Garcia JJ, Toledo AH, Misawa K, Gomez-Alonso A, et al. Tacrolimus down regulates free radical tissue levels, serum cytokines and neutrophil infiltration after severe liver ischemia. Transplantation. 1997;64:594-8.

15. Lee JI, Ganster RW, Geller DA, Burckart GJ, Thomson AW, Lu L. Cyclosporine A inhibits the expression of costimulatory molecules on in vitro generated dendritic cells: association with reduced nuclear translocation of nuclear factor kappa B. Transplantation. 1999;15: 1255-63.

16. Kalibori M, Sakitani K, Oda M, Kamiyama Y, Masu Y, Nishizawa M et al. Immunosuppressant FK-506 inhibits inducible nitric oxide synthase gene expression at a step of NF kappa B activation in rat hepatocytes. J Hepatol. 1999;30:1138-46.

17. Aoki Y, Kao PN. Cyclosporine A sensitive, calcium signaling represses NF- $\kappa$ B activation in human bronchial epithelial cells and enhances NF- $\kappa \mathrm{B}$ activation in Jurkat T cells. Biochem Biophys Res. 1997;234:424-31.

18. Baldwin AS. The NF- $\kappa \mathrm{B}$ and $\mathrm{I} \kappa \mathrm{B}$ proteins: new discoveries and insights. Ann Rev Immunol. 1996;14:649-81.

19. Halestrap AP, Connern CP, Griffiths EJ, Kerr PM. Cyclosporine A binding to mitochondrial cyclophillin inhibits the permeability transition pore and protects hearts from ischemia-reperfusion injury. Mol Cell Biochem. 1997;174:167-72.

20. Griffiths EJ, Halestrap AP. Further evidence that cyclosporine A protects mitochondria from calcium overload by inhibiting a matrix peptidyl-prolyl cis-trans isomerase: implication for the immunosuppressive and toxic effects of cyclosporine. Biochem J. 1991;274: 611-4.

21. Massoudy P, Zahler S, Kupatt C, Reder E, Becket BF, Gerlach E. Cardioprotection by cyclosporine A in experimental ischemia and reperfusion-evidence for a nitric oxide-dependent mechanism mediated by endothelin. J Mol Cell Cardiol. 1997;29:535-44.

22. Toung TJ, Bhardwaj A, Dawson VL, Dawson TM, Traystman RJ, Hurn PD. Neuroprotective FK-506 does not alter in vivo nitric oxide production during ischemia and early reperfusion. Stroke. 1999;30: $1279-85$.

23. Soda Y, El-Assal ON, Yu L, Nagasue N. Suppressed endothelin 1 production by FK-506 and cyclosporine $\mathrm{A}$ in ischemia-reperfusion of rat small intestine. Surgery. 1999:125;23-32.

24. Churchill PC, McDonald FD, Ellis VR. Mechanism of cyclosporine A-induced renal vasoconstriction in the rat. J Pharmacol Exp Ther. 1989;250:896-901.

\section{Discussion}

Dr Stuart W. Jamieson (San Diego, Calif). Few here will remember that for the first clinical lung transplants, 20 years ago now, all the donors were brought into the adjoining room for harvesting of the heart-lung block. Needless to say this caused considerable tactical problems, particularly in flying bodies across state lines. It was clear to everybody that better understanding of lung injury would be required to make clinical lung transplantation an effective therapy. In late 1982 we started to use modified Euro-Collins solution for lung protection, and the first long-distance lung procurement was done in December that year. Our group in San Diego has continued to use that solution exactly as formulated then, and we are comfortable with ischemic times as long as 8 hours. But most things could probably be improved, and this is important work that is well presented. It confirms that, as with other organs that are devastated by reperfusion injury, calcium-dependent signaling is an important component in the development of lung ischemia-reperfusion injury, which has been characterized here by alterations in lung vascular permeability, tissue MPO accumulation, and leukocyte transendothelial migration. There is also reduction in the expression of cytokine messenger RNA, which suggests an inhibitory effect on the calcineurindependent expression of NF- $\kappa$ B. That calcineurin inhibitors were ineffective when administered at the time of or after reperfusion further suggests interruption of an early event in the evolution of reperfusion injury, if not of a response to hypoxia itself.

I would appreciate your comments on some areas. Do you have direct evidence regarding the site of the calcineurin effect, whether this is on leukocytes, endothelial cells, or both? If the effect is 
restricted to leukocytes, then most teams are probably already benefitting from this therapy, because the recipient has usually been already treated some hours before reperfusion. But if the effect is primarily on the vascular endothelium, then this would suggest that the donor ought to be treated.

Significant immunomodulation is unlikely to occur with single doses of CSA or FK-506, and you make the point that these agents exhibit differential antiinflammatory and immunomodulatory effects. Do you think that this dichotomy in effects could be related to different sensitivities to the drugs of discrete populations of leukocytes? On a related issue, what do you believe is the key effector cell in this reaction?

Finally, the ribonuclease protection assay demonstrated a generalized decrease in inflammatory cytokine content with both drugs. Have you demonstrated functional roles for these cytokines in lung ischemia-reperfusion injury?

Dr Krishnadasan. Thank you for those insightful comments. With respect to your first question, about calcineurin's effects on leukocytes and endothelial cells, the in vitro data to date suggests, and studies have mostly concentrated on T lymphocytes, that CSA and tacrolimus do have effects at high doses on those types of cells. For inflammatory cells, such as alveolar macrophages and neutrophils, the lower doses of CSA and tacrolimus seem to be effective at blocking NF- $\kappa \mathrm{B}$ activation.

The interesting question of course is what happens to the endothelial cell, and obviously in our whole-organ preparations we cannot sort out what is happening in individual cells. Mulligan's laboratory has turned the opposite way and looked at what is going on in vitro, and it appears that in fact the endothelial cell does play an important role in these reactions. Verrier's laboratory for the last 10 or 15 years also has been doing work indicating that the endothelial cell may be the first cell that is activated. This moves to your second question about the potential effector cell.

We believe that the effector cell in the lung is probably the alveolar macrophage. It is situated in a position that would make it ideally suited to driving the reaction, and in fact when you compare pulmonary artery endothelial cells' and alveolar macrophages' effects on hypoxia and reoxygenation in vitro, we find that alveolar macrophages have a much more robust response to hypoxic stimulus. This makes sense, because the alveolar macrophage is a monocytic cell that produces all the relevant cytokines that we discussed. Again, this dovetails into your third question regarding the ribonuclease protection assay and the functional roles of the cytokines.

Much of my first year in the laboratory was spent defining functional roles for various cytokines, among them TNF- $\alpha$, IL- $1 \beta$, some of the chemokines, macrophage inflammatory protein- $1 \alpha$, MIP-2, membrane cofactor protein 1 , and some $\mathrm{T}_{\mathrm{H}} 2$ cytokines such as IL-4 and IL-10. It appears that the most protection that we are afforded by single cytokine blockade is about a $45 \%$ decrease in lung permeability, which if you compare that with the data that I presented today suggests that the effects of CSA and tacrolimus are more proximal in the cascade and are pretty remarkable compared with single-cytokine blockade.

\section{Authoritative}

The Journal of Thoracic and Cardiovascular Surgery is the most frequently cited thoracic/cardiovascular surgery journal in the Science Citation Index. An article in JTCVS is sited on average almost twice as often as those in the closest cardiothoracic journal. 